\title{
Social and political activity of youth: the content and social and psychological characteristics
}

\author{
Milena Klenova* \\ National Research Saratov State University named after N. G. Chernyshevsky, 410012 \\ Saratov, Russia
}

\begin{abstract}
The purpose of the study presented in this article is to study the social and psychological characteristics of activity of modern youth in the context of its social and political activity. The relevance of the study carried out involves on the basis of theoretical data the necessity to create practiceoriented recommendations aimed at development of social and political activity of youth, taking into account the social demand. An empirical study involved 150 people (at the age of 18 to $27 \mathrm{y}$. o.). The social and psychological study devoted to the study of social and psychological characteristics of social and political activity, helped to establish a number of features that make up the psychological content of this phenomenon. In that way, social and political activity is heavily tied to civic and protest activity, which is confirmed by the obtained correlation relationships. The factor analysis carried out revealed 3 main factors, differentiated by the presence or absence of a load in relation to social and political activity, which we called: "Citizens", "Oppositionists", "Indifferents", that reflect the psychological content of social activity.
\end{abstract}

\section{Introduction}

Today, the issue of youth participation in the political life of the country is becoming relevant again. Social activity as a subject of study has recently dominated in the field of social psychology. Scientists study structural characteristics, factors, determinants that are responsible for the participation of young people in certain types of social activity $[1,2,3]$. Transitivity of modern society, social challenges and protests, widespread and mass dissemination of information regarding political aspects, that are brought into life of an average man through challenges, relevant and problematic posts in the news feed - all these things one way or another arouse a certain interest among the younger generation. To be "in the know", from the point of view of owning information about political life within the country, is becoming trendy. Despite the tendency of discussing and dealing with many pressing and critical problems over the Internet and social networks, we can also notice the increase in the actual desire of young people to participate in political and civil life of the

${ }^{*}$ Corresponding author: milena d@bk.ru 
country. These trends are due to two aspects. On the one hand, various frequent protests and rallies come under notice as they are often attended by teenagers and young people; on the other hand, the State urges the younger generation to be involved in various associations and pro-political organizations (voluntary service organizations, Young Guard of United Russia, etc.). Nevertheless, for social psychology, especially in those matters that relate to the determination of the social, and in particular, the political activity of youth, it is important to study the content of the issue, namely, the study of those social and psychological characteristics of personality that determine the young person's real desire to indulge in domestic political processes. In this scientific study, we will try to answer a number of questions relating to the determination of the modern youth political activity.

\section{Materials and Methods}

The empirical study involved 150 people at the age of 18 to 25 years old. Among them, 50 people are residents of a metropolitan city (St. Petersburg), 50 people are residents of a city (Saratov) and 50 people are residents of a town (Balashov). The following methods were used as methodological tools: unique questionnaire compiled by the author aimed at studying the content of youth social activity, including political activity; a short version of the J. Duckitt's scale (right-wing authoritarianism, faith in a dangerous world, faith in a competitive world); a risk tolerance questionnaire (A. G. Shmelev), a personality protest activity questionnaire (A. Sh. Guseynov), a personality volition questionnaire (N. E. Stambulova). The software package SPSS 17.0 (correlation, factor analysis) was used for statistical processing of the obtained data.

\section{Results}

At the first stage of our study, we analyzed the content of the modern youth social activity. To study social activity, we used unique questionnaire compiled by the author, in which subjects were asked to evaluate their own participation in social and public life, based on classification of social activity by type (altruistic, leisure, social and political, Internet network, civic, social and economic, educational, spiritual, religious, protest, radical protest, subcultural). Respondents rated the degree of their activity for each of the presented types of social activity on a 5-point scale.

Table 1. Social activity assessment 


\begin{tabular}{|c|c|c|c|c|}
\hline & Minimum & Maximum & Average & Std. deviation \\
\hline Altruistic & 1,00 & 5,00 & 2,6047 & 1,13682 \\
\hline Leisure & 3,00 & 5,00 & 4,3488 & 0,71991 \\
\hline Social and political & 1,00 & 5,00 & 2,0233 & 1,22452 \\
\hline Internet network & 1,00 & 5,00 & 3,7907 & 1,40675 \\
\hline Civic & 1,00 & 5,00 & 2,4186 & 1,23890 \\
\hline Social and economic & 1,00 & 5,00 & 2,2093 & 1,26412 \\
\hline Educational & 1,00 & 5,00 & 3,0233 & 1,28152 \\
\hline Spiritual & 1,00 & 5,00 & 2,4884 & 1,29784 \\
\hline Religious & 1,00 & 3,00 & 1,6279 & 0,78750 \\
\hline Protest & 1,00 & 5,00 & 1,2558 & 0,78961 \\
\hline Radical protest & 1,00 & 5,00 & 1,3023 & 0,86009 \\
\hline Subcultural & 1,00 & 4,00 & 1,2093 & 0,67465 \\
\hline
\end{tabular}

Table 1 presents data reflecting subjective assessment of the subjects' social activity. Respondents who took part in the study are more likely to prefer leisure and Internet network activity. This tendency is quite obvious and adequately reflects specific needs of a modern young person aimed at satisfying hedonistic needs. Leisure activities include following: travelling; outdoor recreation; trips to theaters, cinema; watching programs and videos on TV or YouTube; reading books, magazines, other sources of entertainment information; computer games; visiting fitness clubs, health centers, beauty salons; sport classes; street sports; shopping; hobbies; going to cafes, restaurants; spending time in the company of friends, like-minded people, interesting people. We define Internet network activity as activity associated with active participation in various network groups and communities, using your account and communicating via various publicly available resources (comments, reposts, own blogs and publications, chatting in messengers, etc.), an open expression of one's own opinion and position in the virtual environment (in social networks, blogs, a "live journal"), participation in interactive role-playing games with collective interaction. However, despite a rather high subjective assessment of participation in these types of social activity, young people also identify the educational activity as a priority type, which includes the following activities: participation in subject Olympiads; contests; scientific conferences; design and research activities; various educational initiatives, clubs, forums, events ("Total Dictation", "Geographical Dictation", etc.); getting additional education (Palace of Children and Youth Creativity; music and art schools; hobby groups, creative studios; additional professional training); attending developmental trainings, public lectures, master classes and other events aimed at personal development and the acquisition of new skills.

Analyzing the choices of young people regarding preferred types of social activity, we can also note that social and political activity, in comparison with other types of activity, does not dominate, which can indicate to a low interest of respondents in this type of activity. Nevertheless, the average indicator of assessment of their own participation in the social and political life of society among young people, who took part in our study, makes it possible to carry out a social and psychological analysis in terms of contextual characteristics.

The first step in interpretation of contextual characteristics of political activity was the establishment of correlation relationships between the selected type of activity and other types of social activity, which we studied using the presented methodological tools. The obtained correlation relationships demonstrate the interdependence of social and political activity with other types of social activity. The highest numerical correlation indicator is 
established between social and political, civic and altruistic types of social activity. The correlation of social political and civic activity is pretty obvious, since the content of both types of activity includes actions, which are similar in orientation. In other words, social and political activity can be called civic activity with political content and dependence. A correlation indicator that demonstrates the relations between social and political and altruistic activity is quite interesting. Most likely, this indicator reflects a "romanticized" idea of young people about participation in the political life of society. Global, relevant goals that are set within political movements, both pro-government and opposition, give a context in which a young person is given an opportunity to feel part of something big, to do something for the good of society. Additionally, the correlation between protest and social and political activity does not cause contradictions in interpretation. Opposition movements, which are gaining popularity in modern society, are determined primarily by the political order, and the protests that arouse interest among young people are connected specifically with their discontent in social and political life (Fig. 1).

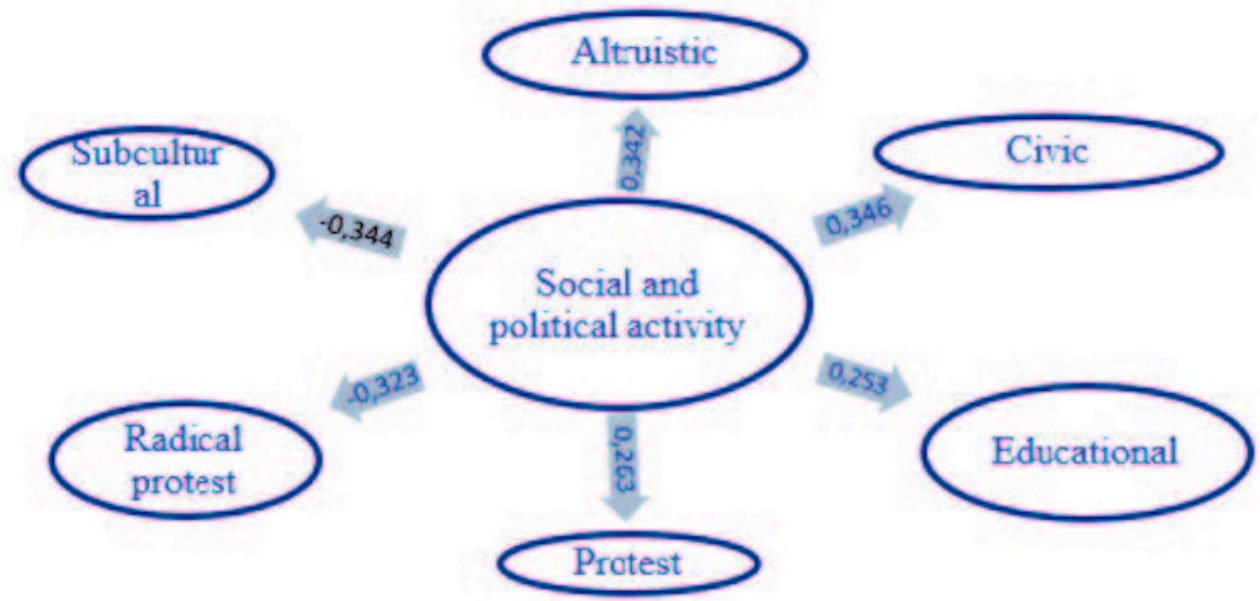

Fig. 1. Correlation relationships of social and political activity with other types of social activity

\section{Discussions}

We used a factor analysis, aimed at identifying the main factors that make up the content of youth social activity, in order to determine the contextual characteristics of social and political activity, taking into account the above mentioned social and psychological characteristics, such as: volitional powers of a person, protest activity, authoritarianism scale, risk tolerance. The factor analysis carried out using the method of principal components followed by Varimax rotation allowed us to identify three factors covering approximately $30 \%$ of dispersion.

The first factor "Citizens" covers $11 \%$ of dispersion and combines indicators reflecting the interest of youth in the field of political and civic activity. From the point of view of substantive content, focusing on this factor, we are faced with an image of a young person whose interests include civic, altruistic, educational and social and political activity, as well as high indicators of emancipation. However, we shall pay attention to indicators with negative values, in particular - almost all the scales that make up the content of protest activity, with the exception of emancipation, as well as the scale of dominance and egalitarianism. Thus, "Citizens" constitute a social category of young people who show interest in political life, but at the same time, this social activity does not imply protest activity 
and is focused on pro-political activity with high rates of faith in the competitive world (on the J. Duckitt's scale).

The second factor, "Oppositionists," covers $10 \%$ of dispersion and combines the social and psychological characteristics of young people with high protest activity, among which we can distinguish high indices of volition (determination, initiative, and independence); in the structure of social activity we can see a tendency towards interest in a protest, radical protest, social and political and social and economic activity. Unlike the previous factor, this factor includes almost all the scales, reflecting the content of protest activity (opposition, nihilism, negativism, escapism) with high positive values, as well as a high risk tolerance.

The third factor "Indifferents" covers $9 \%$ of dispersion and combines indicators reflecting the content of leisure, Internet network, spiritual and educational social activity. This factor does not include a single indicator of protest activity and volition of a person or risk tolerance, and includes only authoritarian submission with high positive indicators in the short version of the J. Duckitt's right-wing authoritarianism scale. This factor reflects the social and psychological content of young people's social activity associated with leisure activities, showing no interest in social and political, protest and radical protest activity.

\section{Conclusion}

Thus, the conducted social and psychological study devoted to the study of the social and psychological characteristics of social and political activity, allowed us to establish a number of features that make up psychological content of this phenomenon. As a result, social and political activity is closely correlated with civic and protest activity, which is confirmed by the obtained correlation relationships. The carried out factor analysis revealed 3 main factors, differentiated by the presence or absence of an intensity in relation to social and political activity, which we called: "Citizens", "Oppositionists", "Indifferents", that reflect the psychological content of social activity.

The study was funded by the grant of the Russian Scientific Foundation (project 18-18-00298)

\section{References}

1. R.M. Shamionov, Russian Psychological Journal, 1(16), 166-188 (2019) doi:10.21702/rpj.2019.1.8

2. E.E. Bocharova, Izv. Saratov Univ., Ser. Educational Acmeology. Developmental Psychology, 4(7), 333-345 (2018) doi: https://doi.org/10.18500/2304-9790-2018-7-4-333-345

3. M.A. Klenova, Society: sociology, psychology, pedagogy, 12. 148-152 (2018) doi: $\underline{\text { https://doi.org/10.24158/spp.2018.12.25 }}$ 